\title{
Marx e Lukács e o problema da individualidade: algumas aproximaçóes
}

Ester Vaisman*

\section{Resumo}

A última grande obra filosófica de Gyorgy Lukács, Para uma ontologia do ser social, assim como Os prolegômenos constituem no interior do marxismo uma inovação radical diante da interpretaçáo dispensada à obra de Marx ao longo do último século, pois têm o mérito de enfatizar o caráter ontológico do pensamento de Marx. Entretanto, se deve sublinhar que, segundo o filósofo húngaro, a categoria da generidade explicita a concepção revolucionária sobre o ser e o devir do gênero humano instaurada por Marx. Lukács identifica o lócus genético dessa concepção, ou seja, a superação do gênero natural mudo e o surgimento do gênero propriamente humano, precisamente na práxis que constitui a maneira segundo a qual a "adaptação ativa" se desenvolve e na qual, por consequência, se realiza de modo contraditório e não idêntico a constituiçẫo processual do ser social. Nesse contexto, Lukács não compreende a individualidade como um dado humano originário, mas, antes, como categoria que se constitui também historicamente, sobre o fundamento de uma "determinação recíproca" com a generidade.

Palavras-chave: Ontologia. Lukács, György, 1885-1971. Individualidade.

* Doutora em Educaçáo pela Universidade Federal de Minas Gerais e professora do Departamento de Filosofia da mesma universidade. 
O desapreço por Marx, derivado do desconhecimento de sua obra e da catástrofe impudente do Leste Europeu, levou inclusive intérpretes bem-intencionados a navegar e submergir em ideias no mínimo problemáticas, quando a grande tematização do homem está em Marx - os indivíduos sociais, a individuação, a formação social da individualidade. $\mathrm{O}$ reconhecimento do forte vínculo entre indivíduo e sociabilidade, quando bem fundamentado, amparado nas formulações do próprio autor ao longo de sua obra, permite-nos compreender que a categoria da individualidade em Marx não é nem pode ser compreendida de outro modo, a não ser recaindo em mitos e supostos naturalistas ou transcendentais.

Por ora, importa lembrar que, já na VI Tese Ad Feuerbach, com objetivo de rejeitar o naturalismo presente em Feuerbach (não obstante a influência exercida por este neo-hegeliano na formação do pensamento propriamente marxiano), Marx é enfático ao afirmar que "[...] a essência humana é o conjunto das relaçóes sociais” (MARX; ENGELS, 2007, p. 534). O conteúdo desse conhecido, mas mal interpretado aforismo, indica uma noção substancialmente diferente das concepçôes naturalistas ou transcendentais, de longa tradição na história da Filosofia. Ademais, tal noção não deve ser tomada como um sociologismo à la Durkheim, em que, como sabemos, o indivíduo é entendido como simplesmente determinado pelo "meio social". Nada mais estranho ao pensamento de Marx, pois é no interior do complexo e contraditório campo da interatividade social, segundo ele, que a individualidade se forja, simultaneamente à produção do próprio mundo social, emergindo, dessa forma, não como dois polos excludentes, mas como âmbitos da existência humana que se determinam mutuamente.

É bem verdade, no entanto, que várias correntes do marxismo, de um lado, não reconheceram a importância do problema, relegado que foi à condição de resquício da fase de juventude de Marx, condenado, portanto, à recusa permanente em nome do cientificismo. Nesse sentido, trata-se de um tema que,

[...] no mais das vezes, encontrou, mesmo em autores marxistas de extrema relevância e competência intelectual comprovada, certo desentendimento. Para alguns, o problema da individualidade foi uma interrogação marxiana 
pertinente nos seus primeiros momentos, ditos do "Jovem Marx", mas que se esgota na medida em que seu pensamento perfaz o caminho à ciência. Seria então o problema da individuação um tema "filosófico", uma preocupação abstrata, que desaparece no desenvolvimento da obra marxiana propriamente científica. Esta posição comparece, grosso modo, na contraposição de uma pretensa "antropologia" marxiana exercitada até 1847 , e a inauguração de uma dada forma de cientificidade com os escritos da maturidade. Para outros comentadores, a categoria da individualidade nem sequer se constitui em problema ou objeto de preocupação para Marx, ressoando este tão-somente como eco fugaz e incongruente com o corpus marxiano. (ALVES, 1999, p. 255-256).

Tendo em vista o quadro delineado na citação acima, fica completamente obnubilado também o fato decisivo de que, embora na atualidade a individualidade tenda a emergir sob o signo da alienação - e assim tem sido tematizada pelas variantes do existencialismo -, seus traços distintivos não podem ser identificados sem mais com uma condição originária inescapavelmente negativa, destituidora, destinada à angústia ou concebida como ser-para-morte. Ao revés, como entificação humanossocietária, ela é tão contraditória quanto o são os vários âmbitos em que o ser humano se constitui. Ou seja, a individualidade é uma entificação histórica, por natureza diversa no tempo e no espaço, desprovida de substância imutável, a despeito do fato de que seja possível vislumbrar aspectos que possam eventualmente permanecer no tempo. Marx o reconhecia, e não raras vezes, em seus textos, se constatam análises ilustrativas na direção de evidenciar que “[...] a individualidade é estabilidade evanescente, compelida à mudança, a transformaçóes constantes, por vezes mais rápidas e imperiosas, outras mais lentas e deliberadas, mas individuação é assentamento tensionado, para o qual mutação e diferencialidade são uma constante" (CHASIN, 2001, p. 56). A individualidade como entificação "compelida à mudança" comparece desde o plano da vida cotidiana até o nível mais espiritualizado da prática 
moral. Comparece desde os vários papéis que o indivíduo assume em sua vida social mais próxima até aqueles que ele pode vir a desempenhar em situaçóes sociais mais amplas e decisivas para o conjunto da sociedade. Náo há como deixar de referir também que a marca da individualidade aparece nas várias formas de manifestação de sentir e pensar, nos desejos e repulsas. No entanto, é conveniente salientar o dilema teórico fundamental que se póe na linha do horizonte dos dias que se seguem: trata-se de algo que se encontra para além da impotente fantasia hedonista, correlata ao conformismo teórico do homem afunilado à pobreza das pulsóes e do imaginário, ou seja, o desafio que está colocado diante de nós é tentar ao menos a recuperação e o desenvolvimento da inteligência que venha a distinguir individuaçáo de individualismo. Enquanto este é a perda do outro - condição única de humanidade -, o primeiro se afirma pelo reconhecimento dos outros - as forças sociais -, enquanto suas próprias forças pessoais. Rumo transgressor, aparentemente impossível de ser considerado nos dias que correm; mas sem outra alternativa no horizonte: é aceitar o desafio ou engrossar a arenga do futuro extinto.

\section{E o caso de G. Lukács?}

Como o filósofo húngaro procurou compreender essa relevante questão?

Em primeiro lugar, não é o caso aqui de retomar em detalhe a extensa e sinuosa trajetória intelectual do autor. De acordo com o testemunho de Tertulian, "[...] a evolução intelectual de Georg Lukács oferece uma imagem singular da formação e do devir de uma personalidade nas condiçóes agitadas de um século não menos singular, por sua complexidade e pelo caráter dramático de sua história” (TERTULIAN, 1971, p. 15).

A dificuldade de determinar em poucas linhas o cerne teórico de Lukács tanto antes de sua adesão ao marxismo, e suas possíveis repercussóes, como depois se deve também ao fato de que o autor "[...] passou por experiências espirituais as mais variadas e heterogêneas" (TERTULIAN, 1971, p. 15), de tal modo que uma das questóes polêmicas é aquela que diz respeito às continuidades e descontinuidades de seu pensamento. Também não é o caso aqui de nos delongarmos sobre esse importante tema, mas não poderíamos deixar de nos referirmos à tese polêmica "[...] daqueles que consideram o 
'verdadeiro Lukács' aquele das obras de juventude e que a fase de maturidade de sua obra, isto é, a fase rigorosamente marxista, constituiria uma involução evidente" (TERTULIAN, 1971, p. 15). Ademais, é fundamental referir outro problema, sempre lembrado e vinculado à trajetória polêmica do autor: suas "autocríticas". Ainda que não seja o momento mais adequado para discutirmos esse problema, seria interessante focalizar o assunto de outro ponto de vista, talvez mais fecundo, indagando o seguinte:

[...] que outro pensador contemporâneo foi capaz de renunciar crítica e deliberadamente, como ele fez por diversas vezes, ao prestígio de obras consagradas? Renúncia que chegou ao total divórcio delas, a ponto mesmo de manifestar completa desidentidade autoral por textos que teriam feito, cada um de per si, a inconfessa e sempre almejada glória de carreira de qualquer um, inclusive dos melhores e mais respeitáveis. Esse desapego, sinônimo de enorme exigência para consigo mesmo, que nunca declinou em arrogância ou pedantismo, nem em autoproclamaçóes de méritos ou em bravatas de auto-suficiência, em que pese a imensa solidão teórica a que esteve constrangido seu trabalho. (VAISMAN, 2005, p. 294).

De todo modo, o que aqui importa ressaltar é que estamos tratando de um dos pensadores marxistas, talvez o mais importante do século XX até os nossos dias, justamente por ter identificado o caráter do tecido teórico instaurado por Marx e, ademais, ter enfrentado a justo título as complexas e contraditórias relaçóes entre gênero e indivíduo. Ora, tal exame se deu particularmente no interior de sua obra publicada postumamente: Para uma ontologia do ser social bem como Os prolegômenos para uma ontologia do ser social. Mas vale a pena, neste momento, apresentarmos a seguinte indagação: por que Lukács insiste em um tema tão inusual em sua obra de plena maturidade? Por uma questão que fatalmente foi recebida com grande estranheza, até por seus discípulos mais diletos? Uma questão que suscitou e vem suscitando recusa imediata de todos os lados, a desaprovação in limini 
de quantos se dizem interessados por assuntos do tipo, que a entenderiam por inadmissível, por que insistir nesse problema "exótico"?

É forçoso reconhecer, antes de mais nada, que o século XX assumiu ou enfrentou o pensamento de Marx a partir do padrão gnosiológico, sem se interrogar se ele era compatível com tal abordagem; supôs que o fosse, com base nos pressupostos da cientificidade corrente. Por outro lado, essa primeira suposição remete a uma segunda, à do acriticismo contemporâneo em geral, por meio do qual a cientificidade repousa e tem de repousar sobre algum tipo de fundamentação gnosiológica (teoria do conhecimento, lógica ou epistemologia).

$\mathrm{Na}$ contramão das tendências dominantes, mesmo no interior do marxismo, as linhas diretrizes da investigação de Lukács são devidas ao reconhecimento marxiano da objetividade como propriedade originária dos entes. Já na fase de preparação de sua Estética, Lukács procurou investigar a base ontológica tanto do pôr estético quanto da recepção da obra de arte.

Ao assinalarmos a provável existência de um fio condutor, principalmente entre a Estética e a Ontologia, não resulta de imediato a conclusão de que Lukács tenha aderido, sem mais, à própria expressão, ainda que, como afirma Oldrini (2002, p. 67), "[...] mesmo lá onde a coisa, o nexo conceitual já exista em germe, falta a palavra para exprimi-lo". Em verdade, Lukács nutria sérias desconfianças e suspeitas em relação à própria palavra, resistindo em utilizá-la; "[...] para ele, tomando a conotação que lhe fora conferida por Heidegger, ela só tem um valor negativo" (OLDRINI, 2002, p. 67). Entretanto, ao entrar em contato com a obra de Ernst Bloch Questóes fundamentais da Filosofia. Pela ontologia do ainda-não-ser (nochnicht-seins), publicada em 1961, e com a volumosa obra de N. Hartmann sobre Ontologia, há uma mudança de postura do autor em relação à palavra. Tertulian (apud OLDRINI, 2002, p. 68), chega mesmo a afirmar “[...] que os escritos ontológicos de N. Hartmann tiveram o papel de catalisador na reflexão de Lukács; eles lhe inculcaram, com certeza, a idéia de buscar na ontologia e nas suas categorias as bases de seu pensamento".

De fato, a partir do depoimento do próprio autor, constata-se esse nexo entre a análise da obra de arte e questóes de ordem ontológica. No prefácio de 1969 à edição francesa de Meu caminho até Marx, o autor afirma: "Se, para a Estética, o ponto de partida filosófico consiste no fato de que a obra de arte está aí, que ela exista, a natureza social e histórica dessa existência 
faz com que toda problemática se desloque para uma ontologia social" (LUKÁCS, 1971, p. 9-31 apud OLDRINI, 2002, p. 69).

Ademais, como veremos à frente, há importantes passos teóricos que indicam a existência, tanto na Estética como na Ontologia e, em particular, nos Prolegômenos, do pressuposto de que a "configuração da conformidade com o gênero" é "[...] determinada em cada caso pelas circunstâncias histórico-sociais", que a "[...] consciência de que o indivíduo pertence ao gênero humano não suprime as relaçôes sociais com a classe"; que "o gênero" é, por sua natureza ontológica, um resultado de forças em luta recíproca postas em movimento socialmente: um processo de lutas de classe na história do ser social"; e, por outro lado, reciprocamente, este processo ganha significado só à luz da teoria do seu desenvolvimento em direção ao "gênero", para utilizar expressóes do próprio autor. (LUKÁCS, 1990, p. 61-62)

Nesse passo, além das advertências feitas anteriormente, em virtude do caráter polêmico tanto da obra quanto de seu autor, é necessário chamar a atenção também para o fato de que a incursão lukacsiana no debate da ontologia não é de modo algum fruto de inclinaçóes particulares ou pessoais, mas surge do reconhecimento da existência de uma série de questóes teóricas que deveriam ser tratadas a partir de uma nova perspectiva. As adversidades de seu tempo impunham a enorme tarefa de retornar a obra de Marx, no intuito de reformular cabalmente as perspectivas teóricas vigentes, de buscar respostas aos descaminhos provocados pela vulgata stalinista que dominou quase toda a tentativa de compreensão teórica dos fenômenos mais importantes do século XX, além das graves distorçôes que provocara na recepção da obra de Marx.

Por isso mesmo, a última grande obra filosófica de Lukács (1984, tradução nossa), Para uma ontologia do ser social, como também seus Prolegômenos constituem no interior da história do marxismo um caso à parte, uma vez que destoa do núcleo comum sobre o qual a obra de Marx foi compreendida ao longo de todo o século passado. Esta obra tem por mérito ter sido a primeira a destacar o caráter ontológico do pensamento de Marx.

Assim é que se pode afirmar que todo o vigor dos escritos ontológicos de Lukács possui duas direçóes básicas: volta-se contra as leituras mecanicistas provenientes principalmente do stalinismo e do marxismo vulgar, ao mesmo tempo em que procura combater a crítica dos adversários de Marx, 
demonstrando como a incompreensão - e mesmo a recusa - de toda e qualquer ontologia se encontra circunscrita em necessidades prementes da própria configuração da sociedade capitalista.

O combate sugerido por Lukács ao predomínio das reflexões lógicoepistemológicas tem, portanto, a perspectiva que concilia a posição teórica com a necessidade prática. Contra o predomínio manipulatório a que se viu reduzida a ciência no mundo do capital, a ontologia recoloca o problema filosófico essencial do ser e do destino do homem e sua autoconstituição contraditória.

Este enfrentamento - teórico e prático - forma a base do argumento que adverte para a necessidade de retorno a Marx, sem as peias erguidas pelo marxismo em geral. Trata-se de varrer das páginas da obra marxiana uma discussão totalmente estranha à sua letra: afirmaçóes que acusam a existência em Marx de um determinismo unívoco, proveniente da esfera da economia, que absolutiza a potência do fator econômico, relegando ao segundo plano a eficácia dos outros complexos da vida social. Ao contrário de um determinismo unívoco da esfera econômica sobre as outras instâncias da sociabilidade, como acusa grande parte de seus adversários, o cerne estruturador do pensamento econômico de Marx se funda na concepção da determinação recíproca das categorias que compóem o complexo do ser social. Nas palavras de Lukács:

Este peculiar, paradoxal, raramente compreendido, método dialético repousa na já acenada convicção de Marx, segundo a qual, no ser social o econômico e o extra-econômico continuamente se convertem um no outro, estando em uma insuprimível interação recíproca, da qual, como mostramos, não deriva nem um desenvolvimento histórico extraordinário privado de leis, nem uma dominação mecânica "imposta por lei" do econômico abstrato e puro. (LUKÁCS, 1984, p. $585)$.

São, portanto, momentos que se apresentam permanentemente em um estado de determinação reflexiva. É a interação e inter-relação destes momentos que constitui a estrutura sobre a qual se move e dinamiza o 
processo de socialização do homem e, consequentemente, da própria individualidade. As categorias da produção e reprodução da vida - esfera econômica - desenvolvem a função de motor central desta dinâmica, todavia, só podem se desenvolver sob a forma de um momento ontologicamente primário de uma interação entre os complexos que vêm a existir na dialética objetiva entre acaso e necessidade. A base econômica permanece sempre como o momento preponderante, no entanto, isso não elimina a relativa autonomia das superestruturas, que se expressa de maneira definitiva na dialética de mútua reciprocidade determinativa existente entre estas e a esfera da economia. Portanto, as esferas superestruturais da sociedade não são simples epifenômenos da estrutura econômica. Longe de constituírem um reflexo passivo, estas estruturas e, sobretudo, o próprio indivíduo podem agir (ou retroagir) sobre a base material em maior ou menor grau, sempre, entretanto, no interior das "condiçóes, possibilidades ou impedimentos" que esta lhe determina.

Tal codeterminação só é possível na exata medida em que, para Lukács, o que caracteriza e determina a especificidade da atividade humana é o fato de ser uma "atividade posta", ou seja, é a configuração objetiva de um fim previamente ideado - pôr teleológico. $\mathrm{O}$ trabalho passa a ser entendido, assim, como a unidade entre o pôr efetivo de uma dada objetividade e a atividade ideal prévia, portanto subjetiva, diretamente regida e mediada por uma finalidade específica. Neste sentido, Lukács define o resultado final do trabalho como uma "causalidade posta", o que significa dizer que se trata de uma causalidade que foi posta em movimento pela mediação de um fim humana e subjetivamente configurado. $\mathrm{Na}$ atividade laborativa, estas duas categorias - subjetividade e objetividade, teleologia e causalidade -, embora antagônicas e heterogêneas, formam uma unidade no interior do complexo. Portanto, de um lado, a causalidade posta, e, de outro, o pôr teleológico, constituem, sob a forma da determinação reflexiva, o fundamento ontológico da dinamicidade de complexos próprios apenas ao indivíduo, na medida em que a teleologia é uma categoria existente somente no âmbito do ser social. Deste modo, definindo o pôr teleológico como célula geratriz da vida social, e vislumbrando no seu desenvolvimento e complexificação o conteúdo dinâmico da totalidade social, Lukács impossibilita a confusão entre as diretrizes e os princípios que regem a vida da natureza e a vida da sociedade: "[...] a primeira é dominada pela causalidade espontânea, não 
teleológica por definição, enquanto a segunda é constituída por obra dos atos finalistas dos indivíduos" (TERTULIAN, 1990, p. 20).

Após estas determinaçóes sobre os fundamentos genéticos da ontologia do ser social, Lukács demonstra como estes mesmos atos teleológicos podem aparecer de forma diferenciada, quando se considera o objeto sobre o qual incidem suas açôes. Entre esses atos, a diferença fundamental se refere fundamentalmente ao objeto sobre o qual exercem sua ação. Os atos teleológicos primários incidem de forma imediata sobre um dado objeto ou elemento natural, enquanto os atos teleológicos secundários têm como finalidade a consciência de outros indivíduos, ou seja, "[...] não são mais intervençôes imediatas sobre objetos da natureza, mas intencionam provocar estas intervençóes por parte de outras pessoas" (LUKÁCS, 1984, p. 46). É a análise destas formas distintas dos atos teleológicos que nos auxilia a compreender o processo de desenvolvimento das fases superiores a partir da forma originária do trabalho. A dinâmica inerente às interaçóes categoriais do trabalho não apenas instaura a origem humana, como também determina a dinâmica das formas superiores da prática social. Nas formas superiores de sociedade, elas ocupam um lugar de destaque, assumindo o papel preponderante na dinâmica deste processo. Os assim denominados atos teleológicos secundários tornam-se mais "desmaterializados", uma vez que se desvinculam da relação direta com o momento material da prática social. São estes atos, também designados por atos socioteleológicos, o lugar genético de dimensôes importantes da prática social, tais como a ética, a ideologia, a arte, e - esta é uma questáo crucial para Lukács - é a partir dela que podemos vislumbrar a gênese das açôes políticas.

Assim, ao examinar com a atençáo devida tanto a Ontologia do ser social como seus Prolegômenos, se torna necessário destacar certos aspectos basilares de seu pensamento tardio - sem a pretensão de esgotá-los, evidentemente -, para que se possa, pelo menos em termos aproximados, identificar a decisibilidade da questão em tela. Senão, vejamos.

Tanto a categoria do trabalho quanto a complexificação da dinâmica da sociedade humana, com o advento das formas superiores da vida social como a formação humana, entendidos no sentido mais lato do termo, são tratadas prevalentemente a partir da determinação recíproca e da superação da heterogeneidade entre teleologia e causalidade. Essas categorias formam, no interior das elaboraçôes lukacsianas, a base analítica de toda e qualquer 
ação do indivíduo humano. Nesse mesmo diapasão, pode-se identificar nesse passo outra tese lukacsiana, intimamente relacionada à primeira: todo o processo social é posto em movimento por meio das açóes teleológicas individuais, mas que em sua totalidade estes atos não possuem uma finalidade determinada, resultando daí todo um movimento que opera por meio de nexos causais espontâneos. Afirmação que nos leva, portanto - e aqui convém ressaltar esta determinação com toda a clareza -, a entender que, no plano da totalidade do ser social, está presente toda uma malha de nexos que atuam sob a forma de uma causalidade social. Fato que leva o pensador húngaro, com essas determinações, a assumir uma posição contrária a tendências no interior do próprio marxismo e contra ainda a filosofia hegeliana, ao asseverar a inexistência de uma teleologia na história.

No nosso ponto de vista, uma das principais contribuiçóes inéditas desses escritos, principalmente os Prolegômenos, diz respeito às relaçóes entre indivíduo e gênero, e que ainda não recebeu o devido tratamento analítico pelos intérpretes.

Lukács (1984, p. 40) assevera que

[...] o lugar central da generidade, a superação de seu mutismo natural, não é de modo algum uma "idéia" genial e isolada que tenha ocorrido ao jovem Marx. Embora a questão raramente apareça, abertamente com essa terminologia explícita, em suas obras posteriores, Marx nunca cessou de avistar no desenvolvimento da generidade o critério ontológico decisivo para o processo de desenvolvimento humano.

Segundo o filósofo húngaro, a categoria da generidade explicita a concepção "revolucionária sobre o ser e o devir do gênero humano" (LUKÁCS, 1984, p. 40) instaurada por Marx. Lukács identifica o lugar genético dessa concepção, isto é, da superação do gênero mudo natural e o advento do gênero propriamente humano, precisamente na práxis individual que constitui o modo por meio do qual se processa a "adaptação ativa" e a partir da qual se dá, de modo contraditório e desigual, a constituição processual do ser social, nos seus dois âmbitos, ou seja, o âmbito do indivíduo e o do gênero. Em outros termos, “[...] a base ontológica do salto [do gênero mudo para o gênero não-mais- 
mudo - E. V.] foi a transformação da adaptação passiva do organismo ao ambiente em uma adaptação ativa, com o que a sociabilidade surge como nova maneira de generidade" (LUKÁCS 1984, p. 43). Nesse contexto, a individualidade não é entendida por Lukács como um dado humano originário, mas uma categoria que se constitui também historicamente, na base de uma "determinação recíproca" com a generidade, mas não só. Trata-se de um processo extremamente lento, inclusive, das próprias relaçóes sociais, para que o problema da individualidade possa aparecer não só como um problema real, mas também universal. Ademais

[...] o verdadeiro desenvolvimento da individualidade [...] é um processo altamente complexo, cujo fundamento ontológico é formado pelos pores teleológicos (teleologischen Setzungen) da práxis com todas as circunstâncias, mas que não tem ele próprio, em absoluto, caráter teleológico. (LUKÁCS 1984, p. 44 , grifos do autor).

Enfim, estamos diante de um processo que se desenrola tanto no sentido objetivo quanto subjetivo, ou seja,

[...] devido à práxis, o ser humano, que se forma numa multiplicidade cada vez mais variada, se defronta com uma sociedade [...] em que não apenas se desenvolve a corporificação objetiva da generidade, tornando-a cada vez mais variada em muitos aspectos, mas ao mesmo tempo coloca múltiplas e diferenciadas exigências ao indivíduo humano nela praticamente ativo. (LUKÁCS, 1984, p. 45).

Vale dizer, a um dado ponto do evolver da sociabilidade, há uma multiplicidade quase infinita de decisóes alternativas que o indivíduo singular da sociedade é constantemente provocado, ou mesmo impelido, a tomar, dadas a diferenciação e a complexificação da sociedade no seu conjunto. Enfim, é importante ressaltar que, ao se debruçar sobre a convergência ou divergência entre desenvolvimento social e individual, tudo indica que Lukács não concebe a formação dos indivíduos humanos como meros produtos mecânicos do gênero, caso contrário, se apagariam os traços específicos do ser social, e restaria apenas a relação natural muda entre espécie 
e seu exemplar. Analisemos a seguir, com um pouco mais de detalhe esse complexo de problemas.

Em primeiro lugar, dado que a generidade, além de ser identificada com a noção de gênero humano elaborada por Feuerbach (1988) em A essência do Cristianismo ${ }^{1}$ (o que tem prejudicado, por exemplo, a devida interpretação dessa categoria nos Manuscritos parisienses de Marx), é diretamente associada a posturas de ordem idealista, Lukács procura demonstrar desde logo que as categorias lógicas como universalidade e singularidade, presentes de maneira importante na Ciência da lógica de Hegel, não possuem necessariamente tal natureza, sobretudo, quando se tem em vista o modo como elas emergem na reflexão marxiana. Nesse sentido, Lukács, ao tomar como referência o manuscrito Crítica da Filosofia do Direito de Hegel (MARX, 2005)², é enfático ao afirmar que:

[...] o erro idealista consiste em ver na universalidade, na generidade não uma expressão do ser, mas uma simples determinação do pensamento (uma abstração). Esta "abstração", ao contrário, não é nunca destacável da essência verdadeira da objetividade existente, portanto, uma determinação do pensamento apenas em termos secundários, derivados. (LUKÁCS, 1990, p. 41).

Portanto, quando se tem em mira identificar o cerne das categorias de generidade e individualidade a partir de uma posição ontológica, a ênfase recai sobre a objetividade, parâmetro de toda forma de cognição, que, por sua constituição intrínseca, determina secundariamente o ser das categorias. Assim sendo, mesmo como "abstraçóes", são concebidas como daseinformen, formas de ser, no dizer do Marx dos Grundrisse, quando confrontado novamente com a especulatividade hegeliana.

Depois de esclarecer a natureza das categorias universalidade e singularidade, correlatas que são às da generidade e individualidade, estamos longe do quadro especulativo em que elas se apresentam como pontos extremos do andamento silogístico, como oposiçôes lógicas. Aparecem agora como determinaçóes da própria objetividade, e não como projeção da subjetividade cognoscente sobre as entificaçóes efetivamente existentes. Tal passo analítico se mostra decisivo para o desenvolvimento argumentativo posterior. 
O próximo passo de Lukács é o de diferenciar a individualidade natural daquela social. Tal como o primeiro, essa diferenciação é relevante, pois abre caminho para a tematização que aqui nos importa. A esse respeito, Lukács não deixa margem para dúvidas: o processo de constituição da individualidade é longo e complicado na exata medida em que é fundado sobre os pôres teleológicos da atividade, em qualquer nível que ela se desenvolva. Assim, se pronuncia ele a respeito:

[...] ocorre um longo desenvolvimento das relaçóes sociais, que inicialmente é lentíssimo, para fazer emergir como real e, sobretudo, como universal o problema da individualidade [...] Assim, em conseqüência da práxis, o ser humano, que prossegue seu desenvolvimento em termos multilaterais sempre mais desdobrado, se encontra defronte a uma sociedade e a seu intercâmbio orgânico com a natureza, a sua produção de órgãos de autoconservaçáo, etc. mediante os quais a corporificação objetiva da generidade não apenas se desenvolve, se torna sempre mais variada sob muitos perfis, mas, por outro lado, coloca exigências sempre mais numerosas e diversificadas aos homens singulares, em que são ativos [...] Esse processo, que se desenvolve no plano subjetivo e objetivo, na constante interação entre subjetividade e objetividade, é aquilo que faz nascer as bases ontológicas por meio das quais a singularidade originária do homem, em vários aspectos ainda simplesmente natural, pode assumir pouco a pouco o caráter da individualidade (que é social, que é possível somente na sociabilidade). (LUKÁCS, 1990, p. 45-46)

Temos na citação acima importante caracterização não só a respeito do caráter histórico da individualidade, mas também de seus laços constitutivos com a atividade concreta dos próprios indivíduos. Assim, além de sua dimensão histórica, a individualidade é um processo que se constitui a partir da prática que se dá em sociedade. Trata-se, é bom frisar, de um processo constitutivo tanto do plano subjetivo quanto do objetivo simultaneamente, o que implica reconhecer a construção da individualidade a partir das 
respostas singulares práticas que se verificam em decorrência das múltiplas exigências que o mundo social coloca para agentes singulares. Ora, como já nos referimos linhas acima, o lócus genético dessas demandas e respostas é o trabalho, entendido por Lukács, como já vimos, como fenômeno originário da vida social. Aqui, a relação entre sujeito e objeto que emerge no âmbito do trabalho provoca mudança estrutural completamente nova "em termos ontológicos", precisamente "na inter-relação entre os processos reprodutivos singulares e o seu conjunto", tornando-se o "[...] fundamento objetivo de toda generidade ao nível do ser da sociabilidade" (LUKÁCS, 1990, p. 53).

Portanto, do lado objetivo, tem-se a relaçáo entre sujeito e objeto nascida no trabalho como constitutiva da sociabilidade, ou seja, da generidade. Do lado subjetivo, Lukács enfatiza, a partir desse mesmo complexo, a multiplicidade e a infinitude de decisóes alternativas que os indivíduos singulares são constantemente impelidos a tomar, diante dos problemas sociais que a cada vez assumem complexidade maior, em decorrência da própria diferenciação interna da sociedade. Lukács (1990, p. 55) denomina esse processo de "[...] fundamento social daquilo que costumamos chamar, detendo-nos nos aspectos mais gerais, de educação do homem para a individualidade". Ou seja, além de desempenhar papel fundante no processo de formação social da individualidade, o caráter essencialmente ativo da existência humana contribui de modo decisivo para a "educação do homem para individualidade". Essa assertiva de Lukács é altamente instigante, pois coloca o problema em seus devidos termos: a individualidade não é mero reflexo passivo das assim chamadas condicionantes sociais, mas é algo que se forma e, nesse contínuo formar-se, é ressaltada a dimensão educacional, que ocorre, bem entendido, no interior das complexas vivências das "decisóes alternativas", ou seja, nas escolhas que se fazem nos vários planos da existência social, desde a vida cotidiana até as decisões de cunho ético e político.

Dito de outro modo, a personalidade de cada indivíduo é resultado da escolhas que ele realiza ao longo da vida. Se tais escolhas são realizadas a partir de um "campo de possíveis", isso não modifica no essencial a questão decisiva aqui apresentada, ou ainda, nas palavras do próprio autor: "[...] o curriculum vitae de qualquer ser humano é constituído de uma cadeia ininterrupta, que, porém, não é constituída de uma simples seqüência de diferentes decisóes heterogêneas, mas se 
refere de forma contínua e espontaneamente ao próprio sujeito dessas decisôes" (LUKÁCS , 1990, p. 59, grifos do autor). Vale dizer, mesmo que tais decisóes sejam tomadas em meio às possibilidades efetivamente existentes, e não a partir de uma "vontade transcendental", tais decisóes carregam aspectos diretamente vinculados à subjetividade que as tomou. É nessa medida que nos sentimos autorizados a afirmar que a dimensão mais relevante da formação da individualidade é sua autoconstituição, pois se trata, finalmente, de um só e único processo que diz respeito tanto à constituição do gênero quanto do indivíduo, no interior do qual a dimensão ativa, que é atributo específico da existência humana, se encontra circunscrita apenas pelo próprio indivíduo.

\section{Notas}

1 Nessa obra, como é sabido, Feuerbach procura explicar a essência do cristianismo, não pela via teológica, mas por uma essência antropológica. Por esse motivo, os primeiros capítulos do livro são consagrados à determinação da essência genérica do ser humano.

2 Nesse manuscrito, Marx formula a crítica ontológica à filosofia especulativa. Encontram-se ao longo do texto severas restrições ao logicismo hegeliano.

\section{Referências}

ALVES, A. J. L. A individualidade nos Grundrisse de Karl Marx. 1999. Dissertação (Mestrado em Filosofia) - Faculdade de Filosofia e Ciências Humanas da Universidade Federal de Minas Gerais, Belo Horizonte.

CHASIN, J. Ad hominem: rota e prospectiva de um Projeto Marxista. São Paulo: Estudos e Ediçóes Ad Hominem, [2001] . (Ensaios Ad Hominem, IV).

FEURBACH, L. A essência do cristianismo. Campinas: Papirus, 1988.

LUKÁCS, G. Prolegomena zur ontologie des gesellschaflitchen Seins. In: . Zur ontologie des gesellschaftlichen Seins: I. Halband: Luchterhand Verlag, 1984. 
LUKÁCS, G. Prolegomeni all'ontologia dell'essere sociale. Milano: Guerini e Associati, 1990.

LUKÁCS, G. Zur Ontologie des gesellschaftlichen Seins: II. Halband:

Luchterhand Verlag, 1984.

MARX, K. Crítica da filosofia do direito de Hegel. São Paulo: Boitempo, 2005.

MARX, K; ENGELS, F. A ideologia alemã. São Paulo: Boitempo, 2007.

OLDRINI, G. Em busca das raízes da ontologia (marxista) de Lukács. In: PINASSI, M.O.; LESSA, S.(Org.). Lukács e a atualidade do marxismo. São Paulo: Boitempo, 2002. p. 67.

TERTULIAN, N. L'Évolution de la pensée de Georg Lukács. L'Homme et la Societé, Paris, n.20, p. 15, avr./juin.1971.

TERTULIAN, N. Introduzione. In: LUKÁCS, G. Prolegomeni all'ontolologia dell'essere sociale: questioni di principio di un'ontologia oggi divenuta possible. Milano: Guerini e Associati, 1990. p. XX.

VAISMAN, E. O “jovem” Lukács: trágico, utópico, romântico? Revista Kriterion: Revista de Filosofia, Minas Gerais, v. 46, n. 112, p. 293-310, 2005. 


\section{Marx and Lukács and the problem of individuality:} some approximations

\section{Abstract}

The last great philosophical work of Gyorgy Lukács, The Ontology of Social Being, as well as Os prolegômenos [The Short Ontology] constitute a radical innovation within Marxism of the interpretation of Marx's work, because they emphasize the ontological character of Marx's thinking. According to the Hungarian philosopher, the category of genus explains the revolutionary conceptualization of the being and devir of the human genus developed by Marx. Lukács identified the genetic locus of this conception, that is the overcoming of the natural genus changes and the rise of the specifically human genus emerges, precisely in the praxis that constitutes the form in which "active adaptation" takes place and in whi$\mathrm{ch}$, as a consequence, it is conducted in a contradictory and distinct form from the procedural constitution of the social being. In this context, Lukács does not understand individuality as original human data, but, first as a category that is also historically constituted on the foundation of a "reciprocal determination" with genus.

Key words: Ontology. Lukács, György, 1885-1971. Individuality.

\section{Marx et Lukács et le problème de l'individualité: quelques rapprochements}

\section{Résumé}

Le dernier grand ouvrage philosophique de Gyorgy Lukács, Pour une ontologie de l'être social, ainsi que Les Prolégomènes constituent, à l'intérieur de l'histoire du marxisme, une innovation radicale face à l'interprétation dispensée à l'œuvre de Marx tout au long du dernier siècle, car ils ont pour mérite souligner le caractère ontologique de la pensée de Marx. Cependant on doit souligner que d'après le philosophe hongrois, la catégorie de géneritée explicite la conception révolutionnaire sur l'être et le devenir du genre humain instaurée par Marx. Lukács identifie le locus génétique de cette conception, c'est-à-dire, le dépassement du genre muet naturel et l'avènement du genre proprement humain, précisément dans la praxis qui constitue la manière selon laquelle l'«adaptation active " se développe, et où, par conséquent s'effectue, de façon contradictoire et non identique, la constitution processuelle de l'être social. Dans ce contexte, Lukács n'entend pas l'individualité comme une donnée humaine originaire, mais plutôt comme une catégorie qui se constitue aussi historiquement, dans le fondement d'une "détermination réciproque » avec la géneritée.

Mots-clés : Ontologie. Lukács, György, 1885-1971. Individualité. 


\section{Ester Vaisman}

Departamento de Filosofia - FAFICH

Universidade Federal de Minas Gerais

Av. Antônio Carlos, 6627

CEP:31.270-901 - Belo Horizonte - MG

E-mail: evaisman@fafich.ufmg.br 